\title{
Tumor Vascular Interaction in Melanomas and Neurogenesis: A Review
}

Bhanu lyengar*

Pigment Cell Center, New Delhi, INDIA

*Corresponding author: Dr. Bhanu lyengar, lyengar Farm, Brijwasan Road, PO Kapashera, New Delhi-110037, India, Tel: 91-11-25063433; E-mail: bhanu_i@yahoo.com

Rec date: May 09, 2014; Acc date: June 06, 2014; Pub date: June 08, 2014

Copyright: (c) 2014 lyengar B. This is an open-access article distributed under the terms of the Creative Commons Attribution License, which permits unrestricted use, distribution, and reproduction in any medium, provided the original author and source are credited.

\section{Abstract}

Background: Melanomas arise from multipotent neural crest derivative, the melanocytes. At the tumor-stroma interphase, melanoma cells show organized neural differentiation forming tumor-vascular complexes. The present study explores the sequence of neurogenesis from aurophilic radial glial like cells in relation to angiogenesis, utilizing the tumor-vascular-complex (TVC) as a 3D model.

Methods: Serial frozen and paraffin sections stained with HE, reticulin-gold impregnation for aurophilia; dopa oxidase; immunopositivity for: neural differentiation (nestin, Glial Fibrillary Acidic Protein (GFAP), Neural Fibrillary Protein (NFP), synaptophysin); indoleamines: (serotonin and melatonin), catecholamines (dopamine (DA), Noradrenalin (NA), pigment; Dopa Oxidase (DO)); hormones: ((PRL), Prolactin; (HGH), Human Growth Hormone;) and mitosis. The pattern of neural differentiation in tumor-vascular-complexes (TVC) is assessed by positivity in layer1- layer 5 and cell counts in each layer of the perimantle zone (PMZ).

Statistical Analysis: ANOVA: Kruskal-Wallis One Way Analysis of Variance; All Pairwise Multiple Comparison Procedures [Tukey Test]. [t-test or Mann-Whitney U- test].

Results: A TVC is formed during angiogenic tumor-vascular interaction. Nes +ve angiogenic tubes enter the tumor margins. Periluminar cells show aurophilia, and extend dendritic arbors into the outer layers of the mantle zone. Cells and dendritic processes in layer 1/ layer 2 show Nes, Auro and GFAP positivity. NFP and Syn positivity is seen in layer 4/ layer 5 with a transition zone between layer 2/ layer 3. As two layers accrue, a wave of mitotic activity is seen and cells acquire PRL and $\mathrm{HGH}$ and indoleamine positivity. Catecholamine positivity is in layer 4/ layer 5 thus establishing a polarity. Dopamine is positive in layer 3 / layer 4 coinciding with dopa-oxidase which peaks in layer 4 with NA, ACTH positivity in the outer layers is in association with pigmentation in layer $4 /$ layer 5.

Discussion: Thus during tumor-vascular interaction, melanoma cells differentiate into aurophilic radial glial like cells, as during embryonic neurogenesis, Nes, a marker of multi-lineage progenitor cells, identifies them as MASC, which differentiate into neuronal cells. The angiogenic vessel confers polarity and an embryonal microenvironment in the perivascular mantle zone of the TVC, inducing aggressive melanoma cells to function as neuronal stem cells recapitulating neurogenesis of bio-aminergic cells. The cell cycle is orchestrated by the three pituitary hormones, $\mathrm{PRL}, \mathrm{HGH}$ and $\mathrm{ACTH}$. The expression of $\mathrm{PRL}$ and $\mathrm{HGH}$ is related to mitotic activity while ACTH and pigment indicate differentiated function.

Keywords: Biogenic amines; Dopaoxidase; Angiogenesis; Nestin; GFAP; Prolactin, Human growth hormone; Adrenocorticotropic hormone

\begin{abstract}
Abbreviations:
VGP: Vertical Growth Phase; P: Pigmented Areas; A: Amelanotic Areas; VM: Vasculogenesis; TVCs: Tumor-Vascular-Complexes; HE: Haematoxyline-Eosin, PAS: Periodic Acid Schiff; DO: Dopaoxidase; DA: Dopamine; NA: Noradrenalin; Ser: Serotonin; Mlt: Melatonin; NAT: N-Acetyl Transferase; HIOMT: Hydroxyindole-Omethyl Transferase; ACTH: Adrenocorticotropic Hormone; POMC: ProOpiomelanocortin; PRL: Prolactin; HGH: Human Growth Hormone; Ach: Acetylcholine; GFAP: Glial Fibrillary Acidic Protein, NFP: Neural Fibrillary Protein Syn: Synaptophysin; INC: Incorporated Vessels; PMZ: Perimantle Zone; Nes : Nestin; Auro: Aurophilia;
\end{abstract}

VEGF: Vascular Endothelial Growth Factor; MASC: Multi-Potent Astrocytic Stem Cell; BDNF: Brain-Derived Neurotrophic Factor

\section{Background}

Melanocytes are derived from the multipotent Neural Crest Cells (NC) which give rise to peripheral neurons, glial cells, and neuroendocrine cell types during embryogenesis of the neural tube [1]. The NC cells arise from the neural fold which lies at the confluence of the neuroepithelium and the general epidermis and so can differentiate into neuronal, epidermal as well as pigment cells. The melanocytes function as pigmented neurons to actively produce catecholamines as well as indoleamines [2-7].

Melanomas are highly malignant tumors arising from the melanocytes in the basal layer of the epidermis, uveal tract of the eyes, inner ear, mucous membrane, genital organs, anus and leptomeninges [8]. Human cutaneous melanomas show molecular plasticity and often 
express genes characteristic of neural cell lineages [9]. Neuronal differentiation with expression of neuron-associated markers such as intermediate filament protein peripherin, neuropeptide substance $\mathrm{P}$, muscarinic acetylcholine receptors, and neuron-specific enolase in primary and metastatic melanomas has been shown in some studies $[10,11]$.

The ability of melanoma cells to undergo proliferation in three dimension is clinically known as the Vertical Growth Phase (VGP). The tumors in the VGP extend into the lower half of the reticular dermis and the net direction of growth tends to be perpendicular to that of the Radial Growth Phase (RGP). It has been observed that tumors having the characteristics of the RGP do not metastasize, while those of the VGP do. VGP melanoma is a highly angiogenic and proliferative lesion. Further genetic changes convert melanoma into an invasive tumor capable of three dimensional growth, increased angiogenesis, and metastasis. The RGP and the VGP are the most important determinants of prognosis in melanoma.

In Vertical Growth Phase (VGP) melanomas there is a definite pattern of neural differentiation in relation to angiogenesis on viewing the tumor as a three dimensional system [12]. Although most human cancers persist in situ for months in a prevascular phase, they require efficient vascularisation, for further growth and metastasis [13]. Production of new blood vessels (angiogenesis) and their remodeling are required for the development of the tumor microcirculation [14]. Neoangiogenesis results from the proliferation, sprouting, and migration of endothelial cells within normal tissues adjacent to the tumor. Studies have shown that varying types of vascularisation are evident in melanomas [15-19]. Angiogenesis is predominant in pigmented melanomas, neovascular channels arising from pre-existing stromal vessels at the invasive margins. In the more aggressive amelanotic melanomas, embryonic vasculogenesis predominates [20].

Recent studies demonstrate reciprocal paracrine interactions between astrocytes, endothelial cells and ependymal cells. The present work has been undertaken to investigate whether a similar interaction occurs in melanomas in response to angiogenesis. This study is a sequel to a recent finding that melanoma cells revert to the embryonic pattern of differentiation, with radial glial like cells and neuronal positive cells during tumor-vascular interaction [12]. A combined reticulin gold impregnation is employed to identify glial cells [21]. The present study assesses the development of the tumor vascular complex as an embryonic microenvironment with identified Multipotent Astrocytic Stem Cells (MASC) during tumor cell-vascular interaction. Neurogenesis and expression of pituitary hormones in various layers of tumor cells in three dimensional tumor vascular complexes (TVC) formed in relation to angiogenesis has been assessed.

\section{Materials and Methods}

Nodular melanomas in the Vertical Growth Phase (VGP) were received from the Cancer Surgery Unit of Safdarjung Hospital, New Delhi, fixed in $10 \%$ formol glutaraldehyde. The formaldehydeglutardehyde cold fixation retains the morphology, gives crisp staining and efficient immunohistochemical staining both in frozen as well as paraffin sections. The same blocks can be subjected to electron microscopy as well. On gross examination the total number of pigmented/amelanotic nodules in each tumor was assessed. 10 nodules were sampled from each of 27 tumors to make a total of 270 blocks, in the ratio of pigmented to poorly pigmented nodules in each tumor (Figure 1) sampled below the reticular dermis. As the specimen were received and sampled the blocks were arranged in a grid. Pigment positive cells per 1000 cells were counted in random 10 HPF per block, entered into the grid and the percentage of pigment positive cells in the 10 nodules in each of the 4 pigmented, 19 mixed and 4 amelanotic tumors calculated which varied between $7 \%$ to $95 \%$ positivity.

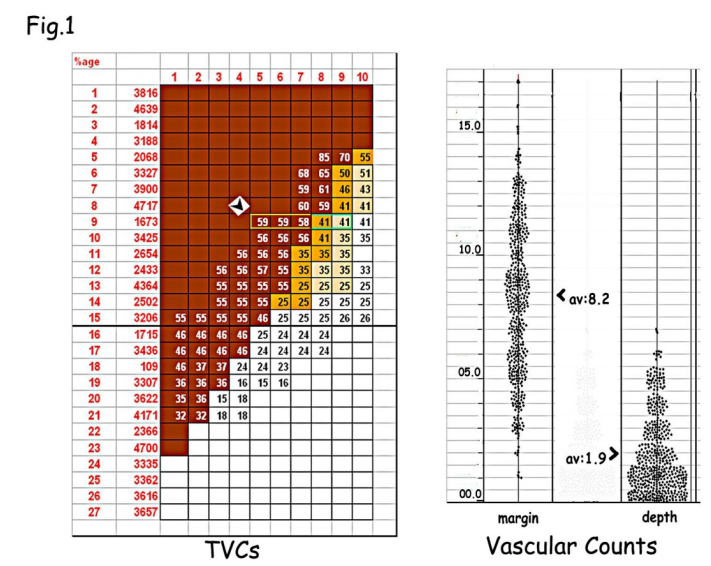

Figure 1: (a) Grid showing blocks arranged in order of pigment levels in the cases studied. Pigmented areas are marked brown, 103 blocks from the tumor-stroma interphase, 51 from pigmented and 52 from poorly pigmented nodules have been marked with the number of TVCs in each.(b) Scatter diagram highlighting the high vascular counts in the marginal $2 \mathrm{hpf}$ as compared with areas in the depth the maximum being $20 / \mathrm{hpf}$.

Serial sections $5 \mu \mathrm{m}$ thick (20-40) frozen sections and paraffin sections were cut from each block and maintained under refrigeration at $4^{\circ} \mathrm{C}$. These were subjected to routine histochemistry, (HE, PAS, modified reticulin+gold impregnation) [21] enzyme histochemistry (Dopa Oxidase) and Immunohistochemistry using the Avidin/Biotin system [22-25]. monoclonal antibodies (mAb)used: HMB45, NFP (neuro filament protein), GFAP, Synaptophysin (Syn), (BioGenex) nestin (Nes), (Chemicon) a marker of multi-lineage progenitor cells [26-29]. The indoleamines: serotonin (SER) \& melatonin (MLT), and the catecholamines: dopamine (DA) \& noradrenalin (NA), by the avidin-biotin method using Dako Pat kits. localization of ACTH, PRL and HGH by the avidin-biotin method using Dako Pat kits. (HMB-45, $\mathrm{PRL}, \mathrm{HGH}, \mathrm{ACTH}$ ) [22-25] as well as the matrix proteins LN5 and integrin.

As negative control all slides included a serial section stained with no $\mathrm{mAb}$. The same $\mathrm{mAb}$ were used simultaneously against known positive sections from human skin as positive controls. Presence of pigment; a positive DOPA reaction; and HMB- 45 positivity are criteria for diagnosis. In the absence of pigment a positive dopa reaction, HMB45 positivity and the presence of premelanosomes on electron microscopy is diagnostic of poorly pigmented melanomas. These criteria form the basis of diagnosing each tumor included in this study.

\section{Vascular counts: (Figure 1)}

Figure (Figure 1a) showing pigmented vs poorly pigmented nodules arranged in a grid in order of the level of pigmentation in the tumors studied. Marginal zone between the tumor and stroma were selected to 
study the tumor/vascular interaction during angiogenesis. 51 blocks are from pigmented and 52 from poorly pigmented nodules (Figure 1).

Vascular channels are counted at the tumor stroma interphase in each of the 103 blocks to a depth of two high power fields and at a depth of 5 to $6 \mathrm{HPF}$ within the tumor in $10 \mathrm{HPF}$ (1030 HPF marginal and $1030 \mathrm{HPF}$ within tumor). A scatter diagram (Figure 1b) compares the number of vessels at the margin and within the tumor. The number of angiogenic vessels is significantly higher at the margin adjacent to the stroma.

\section{General tumor morphology}

General tumor morphology was examined on HE sections as shown in Figure 2 Panel I

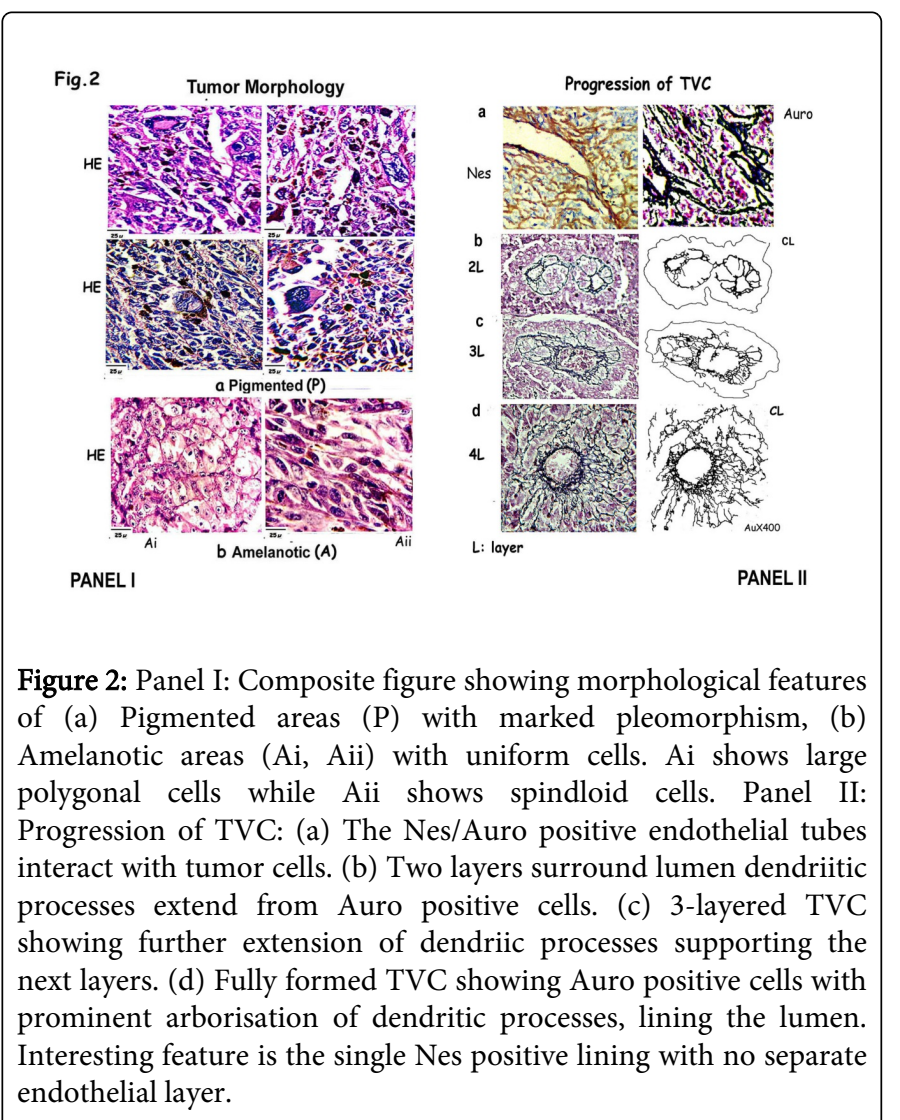

\section{Tumor/vascular Complex (TVC)}

\section{Perivascular mantle zone (PMZ)}

The interacting tumor cells form a mantle around the angiogenic channels at the stroma/tumor interphase forming spheroidal structures. The sequential formation of the tumor vascular complexes (TVC) around a central angiogenic vessel was assessed by gold impregnation in a total of 897 developing complexes and the sequence of appearance of aurophilia and neural, biogenic amines and hormone marker positivity recorded. Of the 897 TVCs 249 show a single layer of tumor cells, 213 show 2 layers, 217 show 3-4 layers while 218 are fully formed with 5 layers.
Since the sequential positivity is being assessed L1 is present in all 897 TVCs, except for Nes which appears only in the single layer stage, L2 in 648, L3\&4 in 435 and L5 in 218 TVCs and the positivity for each marker is collated as percentages for comparison. Positivity for each $\mathrm{mAb}$ in each layer is marked out in Camera Lucida (CL) diagrams. The percentage positivity in each layer is mapped onto an aggregate $\mathrm{CL}$ figure as well in graphs, in the relation to the angiogenic central vessel.

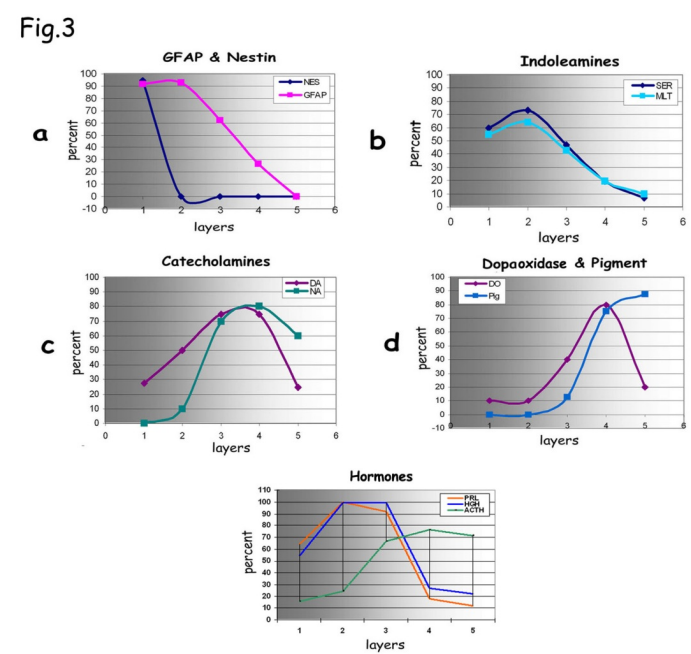

Differentiation in TVCS ANOVA: GFAP/Nes positivity in L1\&L2 was significantly higher than in the other layers $(p<.001)$. Pairwise comparisons of the layers of TVC revealed that the
indoleamines $(S E R / M L T)$ were significantly higher than the catecholamines (DA/NA) indoleamines (SER/MLT) were significantly higher than the catecholamines (DA/NA)

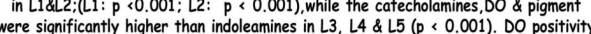
was highest in $L 4(p<0.001)$. Pigment positivity peaked in $L 5(p<0.001)$.
wang

Figure 3: Graphs depicting the organized pattern of differentiation in TVCs. (a) Graph showing GFAP and Nes positivity in L1/L2; (b) Indoleamines, serotonin and melatonin are positive in L2/L3; (c) Catecholamines DA and NA positivity is seen in L3/L4; (d) DO and pigment are positive in L4/L5. (e) Hormones: PRL and HGH are positive in L2/L3 while ACTH in L4/L5.

For the final analyses of global results of all tumors, ten random well formed TVCs with 5 to 6 layers in the mantle zone were studied in serial sections of the 103 blocks for each marker. The distribution pattern of hormone positivity, in relation to the central vessel was assessed, in a total of 1030 TVCs which includes 510 (A) pigmented and 520 (B) with scanty pigment. The layers in each TVC were numbered from L1 to L5 with layer L1 being closest to the vessel. Positivity in each layer was marked out in Camera Lucida (CL) diagrams. The percentage positivity of markers in each layer was mapped onto an aggregate CL figure as well in graphs, to show the marker localization of each in relation to the angiogenic central vessel (Figure 2 Panel II and Figure 4).

Cell Counts: The innermost L1 around the vessel has 15 to 20 cells; the outermost L 5 is formed of 75 to 80 cells, the ratio being 1:5. TVC with 5 to 6 layers are composed of 240 to 250 cells; Percentage of cells 
positive for Auro, Nes, GFAP, NFP, and Syn in each layer is represented as graphs (Figure 3), to show the positivity of each marker in relation to the angiogenic central vessel. Specific morphological features as well as aurophilia and nestin positivity in the different layers of the TVCs have been studied to correlate with the immunopositivity.

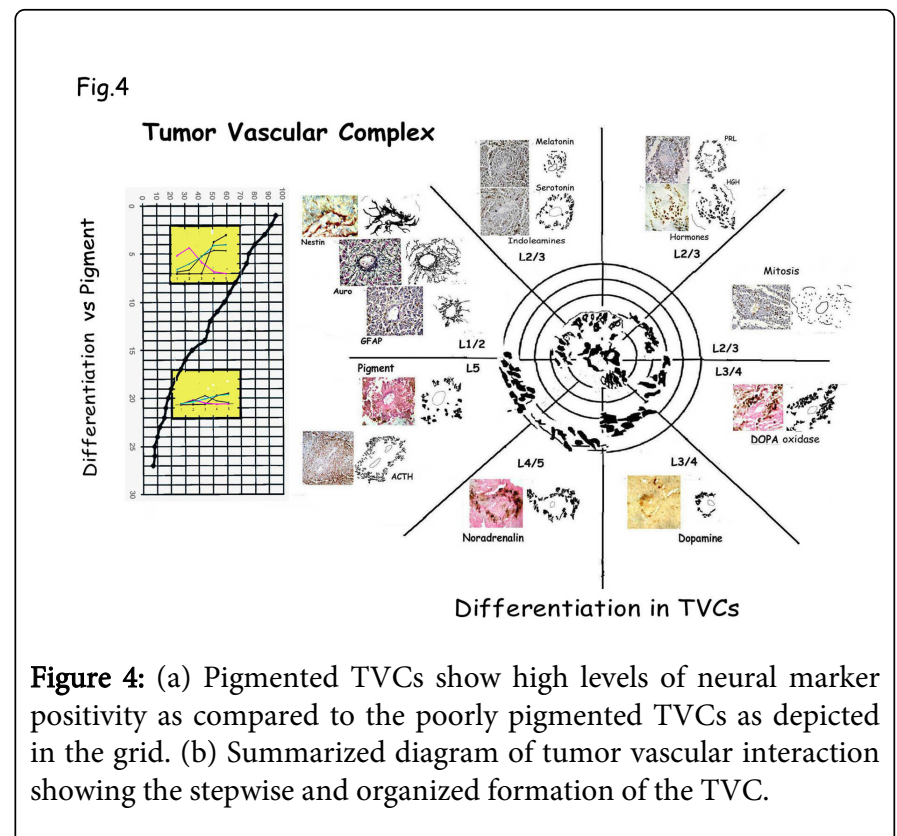

Quantitation: First, the total number of cells in each layer was counted. This was followed by counts of positive cells in each layer. Since the cell numbers vary in different layers, marker positivity has been presented as percentages of positive cells in the total number of TVCs for comparison.

\section{Morphometry: (Figure 5)}

Morphometric analysis of cell and nuclear size and density of the general tumor and TVCs was done using a Semi-automated Zeiss Morphomat, Scion Image of NIH and a Reichert Cytospectrophotometer to compare the size and the nuclear parameters of tumor cells with normal epidermal melanocytes. The nuclear content was assessed as follows: Area of nucleus x optical density x 5 (tissue thickness) $=$ DNA (Q).

\section{General Tumor}

\section{Morphology and Morphometry}

Morphology and morphometry were assessed on HE sections. Morphometric measurements were done on sections from 2 pigmented and 2 amelanotic random nodules in each case. Size of cells and the nuclear parameters in 50-100 cells in 2 random HPF were measured in each section adding up to 200 counts in pigmented and 200 in amelanotic areas per tumor. Measurements in pigmented and amelanotic section are represented as scatter diagrams for comparison. 100 melanocytes from overlying normal epidermis serve as control (Figure 5).

The measurements are taken from each of 6 layers in 5 random TVCs in pigmented and amelanotic nodules in all tumors comparing:
Pigmented nodules; Amelanotic nodules; General tumor cells around TVCs; TVCs in pigmented nodules; TVCs in poorly pigmented nodules; overlying Epidermal melanocytes.

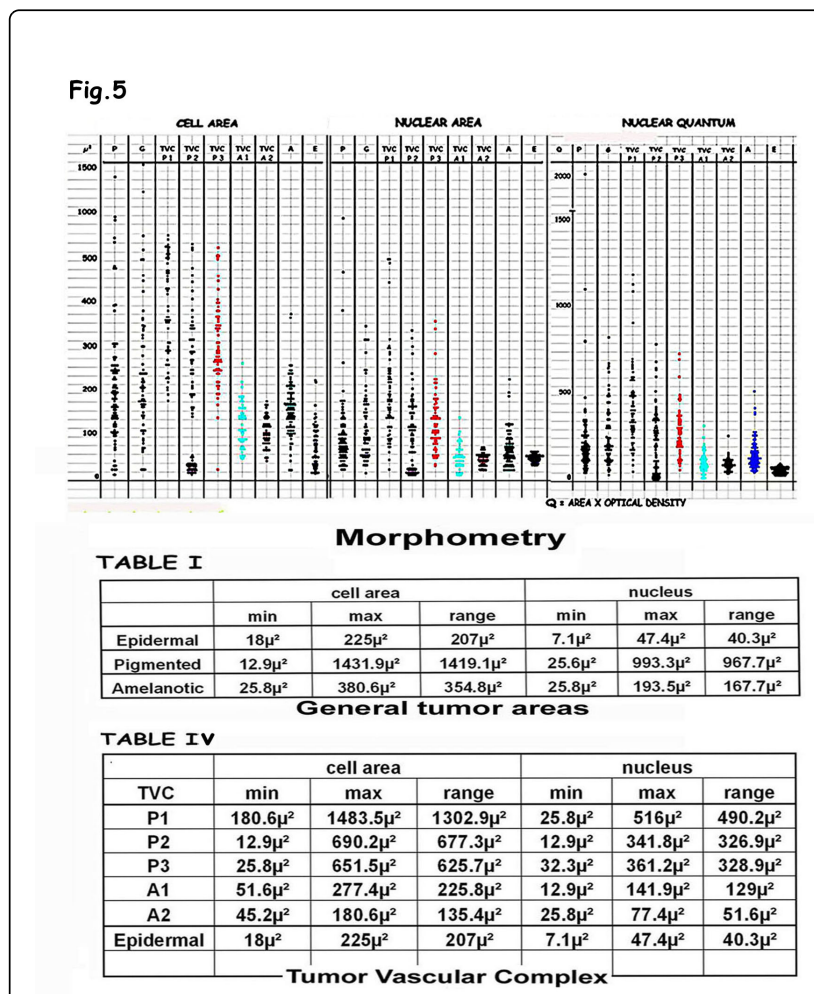

Figure 5: (a) Scatter diagram comparing morphometric parameters in $\mathrm{P}, \mathrm{A}$ and TVCs from pigment and poorly pigmented nodules. There is a graded reduction in cell, nuclear size and DNA from the pigmented nodules, to pigmented TVCs, P1, P2, P3, amelanotic TVCs, A1, A2 and amelanotic nodules. (b) Table comparing morphometric parameters and differentiation from pigmented to amelanotic areas.

Measurements recorded here are from 5 random TVCs each, from 3 pigmented (P1, P2, P3) and 2 amelanotic (A1, A2) nodules in the same tumor (marked with arrow in Figure 1).

Statistical Analysis Anova Analysis: Kruskal-Wallis One Way Analysis of Variance; and Tukey Test: All Pairwise Multiple Comparison Procedures.

\section{Results}

\section{Tumor morphology}

\section{General tumor: Figure 2a Panel I}

Pigmented areas: Component cells show prominent pleomorphism with marked anisocytosis and anisonucleosis (Figure 2a). Cells vary in shape from epithelial, spindloid to rhabdoid to tadpole shaped with areas of round cells and balloon cells. Variable mixtures of both spindle and epithelial cells are seen. Mononucleate with open 
chromatin and multinucleate giant cells with 10-12 nuclei are seen in some areas.

The epithelioid cells are large with eosinophilic cytoplasm with round to oval vesicular nuclei with prominent nucleoli, arranged in a nested pattern separated by thin or dense connective tissue. Some nuclei are dense and hyperchromatic with an indistinct nucleolus. Occasional tumors show isolated areas with small round cells, scanty cytoplasm and dense nuclei, arranged in a rosettoid pattern mimicking primitive neuroectodermal tumors.

Amelanotic areas: show a diffuse pattern of fairly uniform cells (Figure 2b). Balloon cells are identified by their abundant, clear cytoplasm, relatively little nuclear atypia and scanty pigment; and are seen with epithelial cells. The nucleus is large and vesicular with chromatin scattered in irregular clumps. This type of nucleus is mostly associated with a large and prominent nucleolus.

Mixed tumors are formed of multiple variegated nodules some showing heavy pigmentation, others graded peripheral pigmentation and some amelanotic as arranged in the grid (Figure 1).

All tumors showed lympho/vascular/perineural invasion with local lymph node metastasis.

\section{Angiogenesis: (Figure 1b)}

Invasive margin shows significantly higher blood vessels (bv) counts as compared to that well within the tumor growth. On an average $8.18 \mathrm{bv} / \mathrm{hpf}$ are observed within $2 \mathrm{hpf}$ of the invasive margins and an average of $1.9 \mathrm{bv} / \mathrm{hpf}$ in the depth of tumor. At the margins a maximum of $19 \mathrm{bv} / \mathrm{hpf}$ and a minimum of $5 \mathrm{bv} / \mathrm{hpf}$ are observed. In the areas of main tumor growth a maximum of $4 \mathrm{bv} / \mathrm{hpf}$ and a minimum of $0 \mathrm{bv} / \mathrm{hpf}$ are observed. Thus there is a significant difference between angiogenic vessels at the invasive margins and within the tumor. In a rapidly growing tumor the central portions recede from the margins and are deprived of vascularisation.

The formation of the tumor-vascular complex is best outlined by the reticulin-gold impregnation technique [21]. Within the solid tumor interactions between angiogenic vessels and tumor cells are integrated, interactive phenomenon. The mantle zones of the TVCs are the best if not the only indicators of the in situ responses, since no definite tissue/organ culture methods are available to study this dynamic process. As the vessels grow tumor cells first accrue and then proliferate along the length. Cross sections of these vessels, gives a sequential picture of addition of each layer.

The pattern of neural differentiation and cell morphology is regimented and well defined at the tumor/stroma interphase where the tumor cells interact with the neovascular angiogenic vessels. This pattern is lost within the general tumor away from the margins. Nes positive endothelial buds arising from the normal stromal vessels, canalize and extend towards the tumor margin. Nes positivity is seen in $56.25 \%$ in $\mathrm{L} 1$ around the lumen. Nes positivity is first seen along the cell membrane as single cells. As the TVC enlarges positive cells increase from 2 to 15 cells and along the length of the vessel. The cells extend nestin positive dendritic processes in 2-3 layered TVCs, and are well outlined (Figure 2 Panel II).

The luminal cells show aurophilia first in the cell membrane followed by the cytoplasm and by the appearance of a single process extending outwards into the proliferating layers of cells. Some cells are seen to extend processes along the circumference of the vessel. Aurophilic cells extend into L2 as the TVC enlarges and further layers are added on. The aurophilic processes elongate outward along with the increasing concentric layers of tumor cells from L3 to L5. These processes branch and arch over to form a complex supporting framework along with reticulin fibers for the proliferating tumor cells.

The cells showing co-expression of aurophilia and nestin/GFAP positivity in L1 \& L2 resemble the radial glia seen during neurogenesis, nestin being a marker of multi-lineage progenitor of neuroepithelial stem cells [26]. The tumor cells grow out into concentric layers to form a compact spheroid structure, the TVC, composed of 5 to 6 layers of tumor cells demarcated by slender reticulin fibers but no definite basement membrane. The TVCs are clearly demarcated from the surrounding sheets of tumor cells which are pushed aside by the expansile growth. The outer layers show neural differentiation with NFP and Syn positivity (Figures 3 and 4).

As the middle layers, L2/L3 form indole amines and hormones PRL and $\mathrm{HGH}$ are expressed along with prominent mitosis. Both serotonin (71.8\% in L 2. 62.8\% in L3), and melatonin (60.9\% in L2. 64.1\% in L3) are positive the SER positivity being 7 times higher and MLT being 20 times the pigmented TVCs. PRL ( $42.5 \%$ in $\mathrm{L} 2,39.8 \%$ in L3) and $\mathrm{HGH}$ (39.8\% in L1, $48.6 \%$ in L2/L3) in pigmented TVCs, PRL being 8 times and $\mathrm{HGH}, 20$ times higher in pigmented TVCs.

\section{Mitotic counts in TVCs}

Mitosis is mainly concentrated in the layers L2 and L3. 87.7\% [43.75\% mitotic figures] TVCs showed mitotic figures in L2 and $99.2 \%$ (49.3\% mitotic figures) TVCs in L3 and very occasional mitosis L4, L1 and L5.

The TVC enlarges to acquire layers L4/L5 expressing the neural markers NFP/Syn, catecholamines DA, NA, and enzymes DO, Pigment and ACTH. NFP positivity is $38.9 \%$ in L3, $51.7 \%$ in L4 and $50.6 \%$ in L5 positivity being 7 times greater in pigmented TVCs. Syn positivity is 38\% in L3, 62.3\% in L4 and 63.5\% in L5. Pigmented TVCs show 4 times higher Syn positivity.

DOPA oxidase is the crucial triphasic enzyme in catechol metabolism resulting in DA/NA and pigment. DO positivity is higher in the outer layers of the TVCs. The positivity is $84.9 \%$ in the L4 and $96.9 \%$ in L5. DO positivity is very low in the amelanotic TVCs as compared to pigmented TVCs.

DA and NA are expressed in the outer layers. DA positivity (75\%) is in the L3\&4, and 25\% in L5, maximum positivity being in L3 \& L4. NA positivity is $70 \%$ in L3. In the L4 and L5 the positivity increases being $80 \%$ and $60 \%$ respectively.

The interesting feature is the separation of indoleamine and the catecholamine positive cells into different layers as seen during neurogenesis.

Pigment positivity is seen in the outer layers of the TVCs. The layers L1, L2 and L3 do not show any pigment. Positivity is 39.5\% cells in L4 and $60 \%$ in L5. Pigment positivity is very low in the amelanotic TVCs as compared to pigmented TVCs. almost 60 times less than pigmented TVCs.

ACTH positivity is low in the inner layers while maximum ACTH positivity is in the L4 \& L5 is with $64.2 \%$ positive cells \& $61.6 \%$ positive cells, maximum positivity being from L 3 to L5. In poorly pigmented ACTH positivity is low in all the layers compared to pigmented TVCs, positivity being from L3 to L5, 1/10th of pigmented TVCs. 


\section{Morphology}

The cells in the different layers have defined morphologies unlike the general tumor. The L1\&2 with GFAP positivity show dendritic cells radial glia-like cells which extend processes outward into the proliferating layers. In the outer layers L4\&5 Syn positive cells extend processes inwards to resemble neuronal cells.

Occasional neovascular channels remain quiescent with a single layer of GFAP negative tumor cells outside a thin silver positive BM. There is no proliferation as seen with GFAP positive layer. At the tumor margin, the new vessels are surrounded by fibrous tissue and evolve into stromal vessels. The surrounding sheets of tumor cells unrelated to vessels, show scattered GFAP, NFP and Syn positivity but no dendricity.

\section{Morphometry: (Figure 5 scatter and Table 1)}

Morphometry was done to compare the morphometric parameters of pigmented, poorly pigmented from general areas and the mantle zone of TVCs with normal epidermal melanocytes. 5 random TVCs were taken from three pigmented ( $\mathrm{P} 1, \mathrm{P} 2$ \& $\mathrm{P} 3)$ and 2 poorly pigmented areas (A1 \& A2) from the same case for comparison.

The cell and nuclear sizes and range show a gradual reduction from pigmented to amelanotic TVCs as can be seen in fig and table, the parameters being near normal in those from poorly pigmented areas. The component cells of the mantle zone of TVCs are more uniform matching normal epidermal melanocytes, those from pigmented nodules showing a greater scatter due the presence of glial cells.

\section{Statistical analysis}

\section{Neural differentiation}

On Anova Analysis GFAP is significantly higher than NFP/Syn in L1 \& $2((\mathrm{P}=0.030)$. F: 13.885) and significantly lower in L4 \& $5((\mathrm{P}=$ 0.004). F: 59.878 in L4 \& 5). Tukey test: All Pairwise Multiple Comparison Procedures: Comparison:P P<0.050: GF vs. NFP:0.031 Yes; Syn vs. GF:0.004 Yes

\section{Biogenic amines}

Statistically there were significant differences in Dopa Oxidase (DO) positivity in different layers of the tumor vascular complex ( $F$ $371.60, \mathrm{P}<0.001)$. The percentage positivity for DO was the highest in L4 $(80.67 \pm 2.1)$, followed by L3 $(40.0 \pm 3.0)$ while positivity was lower in L5 $(19.67 \pm 3.5)$ and L2 $(10.0 \pm 2.0)$ the lowest positivity being in L1 $(9.67 \pm 2.5)$. Pairwise comparisons revealed that the DO positivity in different layers of the tumor vascular complex were significantly different from each other $(\mathrm{P}<0.001)$.

Pairwise comparisons revealed that the percentage of positivity of the catecholamines, DO and pigment was significantly higher than indoleamines in L3, L4 \& L5 $(\mathrm{P}<0.001)$. There were no significant differences between the catecholamines in L3 \& L4 (DA, $75.0 \pm 3.0$; NA, $70.0 \pm 2.0$ ) while in L5 DA positivity was significantly lower than NA positivity $(\mathrm{P}<0.001)$.

The pattern in L5 was the reverse of that in Layer 1, with SER (5.9 \pm $1.6)$ and MLT $(9.6 \pm 1.5, \mathrm{P}<0.001)$ positivity being significantly lower than DA $(25.0 \pm 2.0)$ and NA $(61.0 \pm 2.6, \mathrm{P}<0.001)$.
Pigment (Figures $3 \mathrm{~d}$ and $4 \mathrm{~d}$ ): positivity is higher in the outermost layers of the PMZ as compared to the inner layers. There is no positivity in L1 \& L2, 12.5\% (54/435 PMZ) in L3. In the L4 and L5 the positivity increases being 75\% (326/435 PMZ) and 87.5\% (191/218 PMZ) respectively Thus peak positivity is in the L5.

Pigment: In comparison, L1 and L2 of the tumor vascular complex were not pigmented. Pigment positivity increased significantly in subsequent layers $(\mathrm{F}=4088.40, \mathrm{P}<0.001)$. There was a significant increase in the amount of pigment from $\mathrm{L} 3(11.67 \pm 1.4, \mathrm{P}<0.001)$, to L4 $(74.67 \pm 1.5)$ thence to peak in L5 $(87.83 \pm 1.5)(\mathrm{P}<0.001)$.

\section{Hormones}

PRL: The percentage of PRL was significantly higher $(t=11.90$; $\mathrm{p}<0.001)$ in Layers $2-3(95.62 \pm 7.504)$ compared with that in Layers 4-5 (15.64 \pm 14.65). (Mean: L2-3: 95.62; L4-5: 15.64. Std Dev: L2-3: 7.504; L4-5: 14.65) Cells in Layers 2-3 expressed significantly higher levels of PRL $(\mathrm{MWU}=4.5 ; \mathrm{t}=52.5, \mathrm{p}=0.026$, median values $=22)$ compared to those in Layers $4-5$ (median value $=2.1$ ). (Mean: L2-3: 21.28; L4-5: 2.18. Std Dev: L2-3: 19.17; L4-5: 2.02)

HGH: The percentage of HGH was also significantly higher (MW$\mathrm{U}=0, \mathrm{t}=57 ; \mathrm{p}=0.002$ ) in layers $2-3$ (median values $=99.5$ ) versus that in layers 4-5 (median values $=24.45$ ). (Mean: L2-3: 99.5; L4-5: 24.45. Std Dev: L2-3: 0.447; L4-5: 24.89) However, there were no statistically significant differences in the levels of HGH $(\mathrm{t}=1.3 ; \mathrm{p}=$ 0.22 ) when cells within layers 2-3 were compared with those in layers 4-5. (Mean: L2-3: 26.16; L4-5: 15.64. Std Dev: L2-3: 7.51; L4-5: 13.47).

ACTH: L4-L5 expressed significantly higher positivity ACTH $(\mathrm{t}=$ $-2.36 ; \mathrm{p}=0.04$, mean $-46.53 \pm 27.92)$ compared to that in L2-L3 (74.62 \pm 8.40 ). ACTH positive cells within L2-L3 did not show statistically significant difference when compared with those in L4-L5 $(\mathrm{t}=1.3 ; \mathrm{p}=$ 0.22). (Mean: L2-3: 16.62; L4-5: 33.95. Std Dev: L2-3: 14.75; L4-5: 25.92).

\section{Discussion}

Melanomas provide a mass of cells as one sees in a 3D matrix. Analysis of the growth patterns would be of benefit for the study of embryonic growth patterns as well as for the study of stem cells. The patterns of neuronal differentiation have been detailed in this work including the localization of neural markers (GFAP, NFP and Syn) by tumor cells in relation to pigmentation. There is a distinct difference between the general tumor matrix and areas of angiogenesis where there is a patterned neural expression and melanocyte morphology.

Melanomas are highly angiogenic and proliferative lesions in the vertical growth phase (VGP) [30,31]. Angiogenesis is the sprouting of blood vessels from preexisting ones where endothelial buds grow out towards the tumor margins [32-36]. Reciprocal paracrine interactions between astrocytes, endothelial cells and ependymal cells have been demonstrated in recent studies. Vascular Endothelial Growth Factor (VEGF) is released from both astrocytes and neurons eliciting a burst of mitotic angiogenesis, which is followed by the production of BrainDerived Neurotrophic Factor (BDNF) by the stimulated microvascular cells [37-39]. In foci of concurrent angiogenesis and neurogenesis, neuronal progenitor cells are spatially associated with mitotic endothelial cells, [40-43].

The cells abutting on the vascular lumen acquire aurophilia, Nes and GFAP positivity first in the cytoplasm, followed by the outward extension of single processes. As concentric layers of tumor cells grow 
out from this layer, aurophilic, Nes and GFAP positive processes extend outward through the layers of tumor cells towards the periphery. The processes form a supporting framework for the extending layers of tumor cells. Occasional processes extend along the circumference of the central vessel. Nes positivity is seen till the formation of 1 to 2 layers, thereafter to be replaced by Auro and GFAP positivity.

Nestin has been the predominant marker used to describe stem and progenitor cells in the mammalian CNS. It is a protein belonging to class VI of intermediate filaments produced in stem/progenitor cells in the mammalian CNS during development, and is expressed mainly in neuroepithelial stem cells but not in mature elements. During neuroand gliogenesis, nestin is replaced by cell type-specific intermediate filaments, e.g. neurofilaments and glial fibrillary acidic protein (GFAP). During embryogenesis, nestin is expressed in migrating and proliferating cells, being restricted to areas of regeneration in adult tissues. Its presence in cells indicates multi-potentiality and regenerative potential.

In neural cell cultures during the first week in culture, approximately $10-30 \%$ of the total cell population stained for the glial cell marker GFAP, and nearly all co-express nestin. Nestinis expressed in endothelial cells of CNS tumor tissues and of adult tissues that replenish by angiogenesis and so can be used as a marker protein for neovascularization [26-29]. This fact is well brought out in the present study, since the endothelial cells lining the angiogenic vessels are positive for Nes as they enter the tumor. As the TVC forms, the L1 cells show Nes positivity as well as GFAP/Auro positivity and resemble radial glia the stem and progenitor cells.

Melanoma cells express characteristics of radial glia, on interaction with the endothelial tubes and further proliferate and differentiate into cells positive for neuronal markers and thus resemble MASC which give rise to neuronal differentiation in neurospheres in cultures [44-65]. At the tumor/stroma interphase the sprouted endothelial tubes cannelise. Initially, a single layer of tumor cells surround the vessels acquire GFAP positivity and extend processes.

Concentric layers of tumor cells grow out from this layer, supported by GFAP positive processes which extend outward through the layers of tumor cells towards the periphery. Where GFAP positivity is absent there is no further proliferation. As the new layers of tumor cells grow out there is a zone where all three markers are co-localized between L2 to L3 followed by NFP and Syn positivity in L4\&L5.

It has been shown that on interacting with the angiogenic vessels, MASC give rise to the full gamut of neuronal differentiation as seen in neurospheres in cultures [56-64]. Neurofilaments, the neuron-specific intermediate filaments localized by NFP positivity for neuronal differentiation form the dynamic axonal cytoskeleton together with other axonal components such as microtubules to maintain and regulate neuronal cytoskeletal plasticity [59]. During development neuroepithelial cells in the neuronal lineage lose nestin and vimentin [60] to express NF-H when the maturing cells are forming synapses [62]. NFP positivity is seen in differentiated ganglion cells, neoplasms of neuronal or mixed cell origin as well as neuroendocrine tumor cells. Ramirez et al. [63] found rabbit choroidal melanocytes, perivascular and intervascular fibers positive for NFP.

Synaptophysin is a vesicular integral membrane protein specifically expressed in neural tissues [64]. Synaptophysin labels small synaptic like microvesicles (SLMV) present in neuroendocrine cells such as the pituitary and adrenal medulla. Synaptophysin and synaptobrevin are abundant membrane proteins of neuronal small synaptic vesicles. These vesicles characterized by synaptophysin contain considerable amounts of the biogenic amines [64,65]. Earlier studies have identified the presence of biogenic amines in melanocytes. These include catechol amines as well as indole amines [2-7].

TVCs show organized expression of biogenic amines in relation to the angiogenic vessel in the middle layers (indoleamines) and in outer (catecholamines) coinciding with increasing Syn positivity [66]. On comparing the levels of positivity in the total number of TVC, GFAP positivity is seen in the layers adjacent to the vessel wall (L1-3). NFP is positive in the peripheral layers (L3-5). Both GFAP and NFP are transitional in L3 equivalent to the 'asterons' described by Steindler DA, 2006 [55]. Syn positivity is highest in L4-5 coordinated with NFP positivity.

Presynaptic Syn/synaptobrevin complex (Syp/Syb-complex) appear during neuronal development $[67,68]$. Thus Syn expression, initiated in the inner layers of the TVC, peaks as the cells differentiate into NFP positive cells. The sequence of progression from radial glia-llke to neuronal positive cells in the TVC simulates the differentiating patterns in in vitro neurospheres and early embryogenesis of the neural tube. The astrocyte-like stem cells have been shown to have the ability to generate neurons $[50,56]$. Work of others has shown that in differentiating from primary floating neurospheres newly-generated neurons can assume or revert to an astrocytic phenotype. In differentiating primary floating neurospheres neurons can shift into cells with astrocyte characteristics by transiting through an "asteron" (neuron/astrocyte hybrid) morphotype which coexpress a variety of neuron and astrocyte proteins and genes [55].

The percentage of GFAP+vity in L1\&L2 correlates with the percentage of NFP/Syn+vity in L4\&L5. In the poorly pigmented PMZ the very low GFAP + vity is associated with a low NFP/Syn + vity. NFP does not increase beyond L3. This is in contrast to the pigmented PMZ where high GFAP + vity in L1/L2 is associated with a similar spike in NFP/Syn + vity in L4/L5 suggesting that the neuronal positivity results from the GFAP + vity after passing through a transitional phase. Thus in those areas where the level of differentiation is low as seen by the absence of pigment, the differentiation of the tumor cells into glial cells on interaction with the neovascular channel is low. This in turn results in low neuronal differentiation.

Neurogenesis is a gradual process that transforms undefined neuroepithelial cells into fully differentiated neurons in two phases: an early, premitotic phase when precursor cells proliferate and adopt a more restricted cell fate; and a postmitotic phase, when neurons are fully committed to a specific cell type [69]. During embryogenesis, the serotoninergic and dopaminergic neurones arise from common progenitors. Biogenic amines have common progenitor stem cells with enzymes cat-1 \& cat- 4 and bas-1 [70-73]. As development progresses, the serotoninergic cells remain at the brain stem and the post-mitotic dopaminergic cells proceed to the midbrain SNC (substantia nigra pars compacta).

Proliferating biogenic amine progenitor cells are specified by the combined actions of two signaling proteins, sonic hedgehog (Shh) and fibroblast growth factor 8 (Fgf8). The combined signaling by these two proteins leads to the induction of the progenitor cells [70]. The mesencephalic DA neurons are generated in the immediate vicinity of two organizing centers, the mid/hindbrain boundary (MHB; also called the isthmus organizer) and the floor plate, a specialized cell type that lies along the CNS ventral midline. The secreted molecules of Shh 
and Fgf8 at the intersection give rise to DA neurons rostrally of the MHB and 5'HT neurons caudally of this boundary. In addition to Shh and Fgf8, 5'HT neurons require signaling by Fgf4, which might be derived from the primitive streak at earlier developmental stages.

Tryptophane is converted to serotonin by MAO and further to melatonin by the light sensitive enzymes NAT and HIOMT during the dark phase [74]. It is observed that the highly dendritic melanocytes in the pigmented proliferative lesions and in melanomas express both serotonin and melatonin in the cytoplasm [75]. These cells show positivity for MAO with tryptamine as substrate. Thus, as in the case of the tyrosine metabolism the melanocytes show the entire machinery for indoleamine metabolism. The conversion of serotonin to melatonin is inhibited on exposure to a pulse of UV indicating the presence of the light sensitive enzymes NAT/HIOMT [5].

The epidermal melanocytes metabolise tryptamine [4] to produce indoleamines on UV exposure in whole skin organ cultures. In the TVC, indoleamines are positive in L2/L3 associated with mitosis. Both serotonin and melatonin are positive in these layers. Conversion of serotonin to melatonin requires photosensitive enzymes HIOMT/NAT which are switched off by light. [74] A high mitotic activity in L2/L3 is a likely source of biophoton emissions of UV. Since this activity is cyclical with light and dark phases, both SER \& MLT are expressed in these layers. In turn, the indoleamines modulate the melanocyte cell cycle in response to UV exposure [4-7].

Tyrosine is metabolised by several cell types which include catecholaminergic neurones in the brain and spinal cord, [76] sympathetic ganglia, adrenal medulla, and melanocytes which are neuroectodermal in origin. The metabolic pathway is through conversion of tyrosine to dopa, by catecholoxidase, a triphasic enzyme which catalyses both wings of dopa metabolism [77]. The catecholaminergic neurones of the locus ceruleus and substantia nigra produce both catecholamines as well as melanin [78]. This feature is observed in sympathetic ganglion cells [79] and occasionally in pigmented lesions of nerve sheath cells and Schwann cells all cells metabolising tyrosine [80]. The dendritic melanocytes in the skin, rich in enzyme positive melanosomes, show tyrosine hydroxylase and dopamine (DA) positivity, Dopamineoxidase (DAO) activity and Noradrenalin (NA) in response to UV exposure [24]. Thus the melanocyte has the enzyme machinery for the conversion of dopa to dopamine and dopamine to noradrenalin. In the skin catecholamines are expressed during S/G2 arrest on UV exposure [81,82]. As with indoleamines, the likely source of $\mathrm{UV}$ is the biophoton $\mathrm{UV}$ released in L2/L3 by the high mitotic activity with a resultant S/G2 arrest in the postmitotic cells in L4/L5 [83].

Cell polarity is essential for generating cell diversity and for the proper function of most differentiated cell types. Neuroblasts divide asymmetrically to result in apical/basal polarity in mitotic neuroblasts, to generate an apical neuroblast and a smaller basal ganglion mother cell (GMC) which undergoes one subsequent cell division to generate neurons or glia [84-86]. Embryonic microenvironments influence development of neuronal stem cells [87-90]. Similarly multipotent tumor cells, fate and plasticity of adult cell are influenced by the microenvironment [91-95]. Multiple cell types which originate from the highly invasive neural crest cell population of the vertebrate embryo can be reprogrammed by simulating a natural environment in 3D organ culture [87,91,96-101]. Human metastatic melanoma cells respond to chick embryo NC-rich microenvironment. Highly aggressive human melanoma cells secrete Nodal, (a potent embryonic morphogen), to induce and form a secondary ectopic embryonic axis in zebrafish [102-104].

As seen in the present study, during angiogenesis in aggressive melanomas, a microenvironment is created in the mantle zone of TVC around the vessel to induce and recapitulate early embryonal neurogenesis of indoleaminergic and catecholaminergic cells, much in the manner of the neural tube as summarized in (Figure 4). The angiogenic vessel confers a polarity to the interacting tumor cells which wrap themselves around.

PRL, HGH and ACTH are not the exclusive products of the pituitary. Ectopic production is commonly seen in several tumor types. It has been observed that PRL and HGH are produced by tongue tumors [105], and colorectal carcinoma cells [106]. Ectopically produced PRL may act as a major local growth promoter via autocrine and paracrine mechanisms. Similarly, there are roughly two types of ectopic ACTH syndrome (EAS): one associated with overt malignancies and the other with occult neoplasms. The prototype of the first condition is Cushing's syndrome sustained by small-cell lung cancer (SCLC), while bronchial carcinoid tumors are the most common occult sources of ACTH.

PRL, Growth Hormone (GH) and placental lactogen are class I helical cytokines believed to have arisen from a common ancestral gene. Prolactin has a dual function - as a circulating hormone and as a cytokine. This understanding is based on PRL production and distinct regulation in extrapituitary sites, binding to membrane receptors of the cytokine receptor superfamily, and activation of signaling pathways that promote cell growth and survival. One of the major targets of prolactin is the skin where it also stimulates skin melanocyte growth. There is increasing evidence that PRL plays a role in several types of cancer in reproductive and non-reproductive tissues via local production or accumulation.

The effects of PRL and GH are mediated through activation of the PRL receptor [PRLR], which belongs to the cytokine receptor superfamily [107]. Activation of PRLR initiates multiple kinase cascades, the most studied of which is the JAK-STAT pathway. Thus PRL induces transcription of members of Cyclin D family, which associate with CDKs 4 and 6 in early G1 phase of the cell cycle leading to cell cycle progression and proliferation $[108,109]$. Associated is an increase in cytosolic calcium concentrations with the progression through the cell cycle and exit from quiescence in early G1 phase, the G1/S transition and other checkpoints during $S$ and $M$ phases [110]. Physiological concentrations (0.5-5nM) of PRL result in an increase in the cytosolic free calcium concentration $(\mathrm{Ca} 2+)$ by stimulating $\mathrm{Ca} 2+$ entry (type I) and/ or inducing a mobilization of calcium ions stored in intracellular compartments (type II) [111]. Besides, there is a direct stimulation of calcium and voltage activated potassium channels (Kca) [112].

Melanocytes also express varying levels of MSH/ACTH in response to UV exposure in correlation with repigmentation and depigmentation as seen in the marginal zone in vitiligo [113]. Melanocortins (MSH) and corticotrophins (ACTH) are both derived from pro-opiomelanocortin hormone (POMC), a large precursor glycoprotein of MW 31000, via a series of enzymatic steps in a tissuespecific manner. Melanocytes contain the full machinery for POMC processing and generation of ACTH and $\alpha-\mathrm{MSH}$ [114]. In this aspect, the melanocytes display a corticotrophin releasing hormone (CRH)led system, organized similarly to that operating at the systemic level. 
Melanocytes respond with enhanced production of cortisol and corticosterone, which is dependent on POMC activity. This is a part of the skin's CRH/POMC system that fulfils analogous functions to the hypothalamic-pituitary-adrenal (HPA) stress axis [115-117]. Melanocytes respond to stress (UV) through production of stress hormones related to HPA axis by secretion of the POMC-derived MSH and ACTH peptides, which increase cutaneous melanin pigmentation. Pigment is, thus, the characteristic feature of a differentiated melanocyte.

All three pituitary hormones were expressed by the proliferating melanoma cells. HGH and PRL are expressed in the inner three layers, predominantly in the 2 nd and 3 rd layers. These were the layers showing a large number of mitotic figures. Pigment and ACTH were typical for in the 4th and 5th layers, where few mitotic figures were observed (Figure 3e). Taken together the results show that areas of proliferation and differentiation are clearly demarcated within the TVC, with proliferation being closer to the vessel and differentiation further from it. PRL and HGH were related to activation of the cell cycle as brought out by the presence of PRL/HGH positivity and mitotic figures in the 2nd and 3rd layer.

Pigment, on the other hand, indicated differentiated function. ACTH positivity was associated with pigment in the 4th and 5th layer. ACTH stimulates pigment production during UV exposure in the epidermis. Is there a possible source of UV in the lobule? Earlier observations on melanocyte dendricity in pigmented basal cell carcinomas and seborrheoic keratosis [83] have shown that mitotic cells are a source of biophoton emissions of UV during the separation of the DNA strands. This correlates with the presence of mitotic figures in the middle layer and with expression of ACTH and pigment in the adjacent outer layers. ACTH holds the cell in the S/G2 phase in which the melanocyte produces pigment $[118,119]$. The absence of abundant mitosis in the outer layers reflects this function of ACTH on the melanocyte cell cycle. In TVC, ACTH/pigment expression limits or pause the growth and enlargement of TVC at the 5th or 6th layer.

It is evident from the above observations that there is a coordinated growth of melanoma cells around neovascular channels, the cell cycle of primitive malignant melanocytes being orchestrated by the expression of the three pituitary hormones - PRL, HGH and ACTH. In the epidermis it is difficult to assign the different roles to each hormone while in the TVC the functions are clearly demarcated. PRL and $\mathrm{HGH}$ initiate a wave of mitotic activity releasing biophoton UV, while ACTH holds the cells in S/G2 phase with pigmentation.

The above findings correlate with expression of neural markers as well as biogenic amines in the TVCs $[12,21,66]$. PRL/HGH positivity associated with mitosis, coincides with the appearance of indoleamines, the presence of melatonin indicating the effect of biophoton emissions during mitosis. Similarly, catecholamine positivity in the outer layers correlates with the S/G2 phase of the cell cycle, presence of ACTH and pigmentation.

\section{Morphometry of TVCs}

TVC counts indicate that their numbers are proportionate to pigment levels in association with level of angiogenesis. Thus the pigmented areas show higher counts as compared to poorly pigmented areas. TVCs taken from a single tumor from pigmented to amelanotic nodules shows a gradation of neurogenesis, the pigmented showing prominent differentiation, with the poorly pigmented showing very low neurogenesis.
For comparison, of morphometric parameters three groups of TVCs (P1,P2 \& P3) are from pigmented and 2 (A1 \& A2) from poorly pigmented areas from the same case from pigmented to amelanotic nodules. The cell \& nuclear size show a gradual reduction from pigmented to amelanotic TVCs, parameters being near normal in those from poorly pigmented areas. The component cells of the mantle zone of TVCs are more uniform matching normal epidermal melanocytes, those from pigmented nodules showing a greater scatter due the presence of glial cells (Table 1). These parameters show a graded change from pigmented to amelanotic suggesting that TVC formation and angiogenesis are linked with melanotic to amelanotic transition. Formation and progression of TVCs has been studied to assess this possibility.

The intriguing features of angiogenesis and TVCs in melanomas are, the presence of normal mitotic figures, the near normal morphometric parameters and a regulated differentiation replicating embryonic neurogenesis of indole and catechol aminergic neurons. The common Nes positive inner layer, continuous with that of endothelial tubes suggests the role of the common origin of neuronal and endothelial stem cells.

\section{Acknowledgement}

I am indebted to:

- The National Institute of Pathology, (ICMR), New Delhi, India for the technical support;

- Dr. KK Pandey, Head, Cancer Surgery, Safdarjang Hospital, New Delhi, India

- Dr. Soumya Iyengar, Additional Professor, National Brain Research Centre, Manesar, India for the Statistical analysis.

\section{References}

1. Kalcheim C, Le Douarin N (1999) The Neural Crest. Cambridge University Press.

2. Iyengar B, Misra RS (1987) Reaction of dendritic melanocytes in vitiligo to the substrates of tyrosine metabolism. Acta Anat (Basel) 129: 203-205.

3. Iyengar B, Misra RS (1988) Neural differentiation of melanocytes in vitiliginous skin. Acta Anat (Basel) 133: 62-65.

4. Iyengar B (1994) Indoleamines and the UV-light-sensitive photoperiodic responses of the melanocyte network: a biological calendar? Experientia 50: 733-736.

5. Iyengar B (1998) The UV-responsive melanocyte system: a peripheral network for photoperiodic time measurements. a function of indoleamine expression. Acta Anat (Basel) 163: 173-178.

6. Iyengar B (1998) Photomodulation of the melanocyte cell cycle by indoleamines. Biol Signals Recept 7:345-350.

7. Iyengar B. (1998) Role of serotonin in Melanocyte Functions. J. Basic Appl. Biomed 6:11-14.

8. Beddingfield FC 3rd (2003) The melanoma epidemic: res ipsa loquitur. Oncologist 8: 459-465.

9. Rifkind RA1, Richon VM, Marks PA (1996) Induced differentiation, the cell cycle, and the treatment of cancer. Pharmacol Ther 69: 97-102.

10. Prieto VG, McNutt NS, Lugo J, Reed JA (1997) The intermediate filament peripherin is expressed in cutaneous melanocytic lesions. J Cutan Pathol 24: 145-150.

11. Lammerding-Koppel M, Noda S, Blum A, Schaumburg-Lever G, Rassner G, Drews U. (1997) Immunohistochemical localization of muscarinic acetylcholine receptors in primary and metastatic malignant melanomas. J Cutan Pathol 24: 137-144. 
12. Iyengar B, Singh AV (2010) Patterns of neural differentiation in melanomas. J Biomed Sci 17: 87.

13. Folkman J (1995) Seminars in Medicine of the Beth Israel Hospital, Boston. Clinical applications of research on angiogenesis. N Engl J Med 333: $1757-1763$

14. Risau W (1997) Mechanisms of angiogenesis. Nature 386: 671-674.

15. Tímár J, Tóth J (2000) Tumor sinuses- vascular channels. Pathol Oncol Res 6: 83-86.

16. Döme B, Paku S, Somlai B, Tímár J (2002) Vascularization of cutaneous melanoma involves vessel co-option and has clinical significance. J Pathol 197: 355-362.

17. Sun BC, Zhang SW, Zhao XL, Hao XS (2003) [Study on vasculogenic mimicry in malignant melanoma]. Zhonghua Bing Li Xue Za Zhi 32: 539-543.

18. Clarijs R, van Dijk M, Ruiter DJ, de Waal RM (2005) Functional and morphologic analysis of the fluid-conducting meshwork in xenografted cutaneous and primary uveal melanoma. Invest Ophthalmol Vis Sci 46: 3013-3020.

19. Zhang S, Zhang D, Sun B (2007) Vasculogenic mimicry: current status and future prospects. Cancer Lett 254: 157-164.

20. Iyengar B, Singh AV (2011) Embryonic vasculogenesis in nodular melanomas and tumour differentiation. Pathol Oncol Res 17: 569-577.

21. Iyengar B (2011) Multipotent Astrocytic Stem Cells Identified During Angiogenesis in Web Central WMC002407.

22. Luna LG (1968) Routine staining procedure. In: Manual of histologic staining methods of the Armed Forces Institute of Pathology. (3rdedtn). Churchill Livingstone, London, UK.

23. Mikel UV (1994) Advanced Laboratory Methods in Histology and Pathology . American Registry of Pathology, Armed Forces Institute of Pathology, Washington DC, USA.

24. Pearse AGE (1985) Histochemistry theoretical and applied. Vol II: Analytical Technology. Churchill Livingstone, London, UK.

25. Prophet ED, Mills B, Arrington JB, Sobin LH (1994) Laboratory Methods in Histotechnology. American Registry of Pathology, Armed Forces Institute of Pathology, Washington DC, USA.

26. Wiese C, Rolletschek A, Kania G, Blyszczuk P, Tarasov KV, et al. (2004) Nestin expression--a property of multi-lineage progenitor cells? Cell Mol Life Sci 61: 2510-2522.

27. Veselska R, Kuglik P, Cejpek P, Svachova H, Neradil J, et al. (2006) Nestin expression in the cell lines derived from glioblastoma multiforme. BMC Cancer 6: 32.

28. Messam CA, Hou J, Major EO (2000) Coexpression of nestin in neural and glial cells in the developing human CNS defined by a human-specific anti-nestin antibody. Exp Neurol 161: 585-596.

29. Suzuki S, Namiki J, Shibata S, Mastuzaki Y, Okano H (2010) The neural stem/progenitor cell marker nestin is expressed in proliferative endothelial cells, but not in mature vasculature. J Histochem Cytochem 58: 721-730.

30. Liu W, Dowling JP, Murray WK, McArthur GA, Thompson JF, et al. (2006) Rate of growth in melanomas: characteristics and associations of rapidly growing melanomas. Arch Dermatol 142: 1551-1558.

31. Shellman YG, Chapman JT, Fujita M, Norris DA, Maxwell IH (2000) Expression of activated $\mathrm{N}$-ras in a primary melanoma cell line counteracts growth inhibition by transforming growth factor-beta. J Invest Dermatol 114: 1200-1204.

32. Folkman J (1971) Tumor angiogenesis: therapeutic implications. N Engl J Med 285: 1182-1186.

33. Norrby K (1997) Angiogenesis: new aspects relating to its initiation and control. APMIS 105: 417-437.

34. Hanahan D, Folkman J (1996) Patterns and emerging mechanisms of the angiogenic switch during tumorigenesis. Cell 86: 353-364.

35. Papetti M, Herman IM (2002) Mechanisms of normal and tumor-derived angiogenesis. Am J Physiol Cell Physiol 282: C947-970.

36. Verheul HM, Voest EE, Schlingemann RO (2004) Are tumours angiogenesis-dependent? J Pathol 202: 5-13.
37. Louissaint A Jr, Rao S, Leventhal C, Goldman SA (2002) Coordinated interaction of neurogenesis and angiogenesis in the adult songbird brain. Neuron 34: 945-960.

38. Shima DT, Mailhos C (2000) Vascular developmental biology: getting nervous. Curr Opin Genet Dev 10: 536-542.

39. Suárez I, Bodega G, Rubio M, García-Segura LM, Fernández B (1994) Astroglial induction of in vivo angiogenesis. J Neural Transplant Plast 5: $1-10$.

40. Palmer TD, Willhoite AR, Gage FH (2000) Vascular niche for adult hippocampal neurogenesis. J Comp Neurol 425: 479-494.

41. Palmer TD (2002) Adult neurogenesis and the vascular Nietzsche. Neuron 34: 856-858.

42. Leventhal C, Rafii S, Rafii D, Shahar A, Goldman SA (1999) Endothelial trophic support of neuronal production and recruitment from the adult mammalian subependyma. Mol Cell Neurosci 13: 450-464.

43. Zerlin M, Goldman JE (1997) Interactions between glial progenitors and blood vessels during early postnatal corticogenesis: blood vessel contact represents an early stage of astrocyte differentiation. J Comp Neurol, 387(4):537-546.

44. Zecevic N (2004) Specific characteristic of radial glia in the human fetal telencephalon. Glia 48: 27-35.

45. Alvarez-Buylla A, Theelen M, Nottebohm F (1990) Proliferation "hot spots" in adult avian ventricular zone reveal radial cell division. Neuron 5: 101-109.

46. Alvarez-Buylla A, García-Verdugo JM, Tramontin AD (2001) A unified hypothesis on the lineage of neural stem cells. Nat Rev Neurosci 2: 287-293

47. Alvarez-Buylla A, Garcia-Verdugo JM (2002) Neurogenesis in adult subventricular zone. J Neurosci 22: 629-634.

48. Barres BA (2003) What is a glial cell? Glia 43: 4-5.

49. Doetsch F, Caillé I, Lim DA, García-Verdugo JM, Alvarez-Buylla A (1999) Subventricular zone astrocytes are neural stem cells in the adult mammalian brain. Cell 97: 703-716.

50. Doetsch F (2003) The glial identity of neural stem cells. Nat Neurosci 6: 1127-1134.

51. Garcia AD, Doan NB, Imura T, Bush TG, Sofroniew MV (2004) GFAPexpressing progenitors are the principal source of constitutive neurogenesis in adult mouse forebrain. Nat Neurosci 7: 1233-1241.

52. Goldman S (2003) Glia as neural progenitor cells. Trends Neurosci 26 : 590-596.

53. Laywell ED, Rakic P, Kukekov VG, Holland EC, Steindler DA (2000) Identification of a multipotent astrocytic stem cell in the immature and adult mouse brain. Proc Natl Acad Sci U S A 97: 13883-13888.

54. Lim DA, Alvarez-Buylla A (1999) Interaction between astrocytes and adult subventricular zone precursors stimulates neurogenesis. Proc Natl Acad Sci U S A 96: 7526-7531.

55. Steindler DA (2006) Redefining cellular phenotypy based on embryonic, adult, and cancer stem cell biology. Brain Pathol 16: 169-180.

56. Laywell ED, Kearns SM, Zheng T, Chen KA, Deng J, et al. (2005) Neuron-to-astrocyte transition: phenotypic fluidity and the formation of hybrid asterons in differentiating neurospheres. J Comp Neurol 493: 321-333.

57. Noctor SC, Flint AC, Weissman TA, Wong WS, Clinton BK, et al. (2002) Dividing precursor cells of the embryonic cortical ventricular zone have morphological and molecular characteristics of radial glia. J Neurosci 22: 3161-3173.

58. Malatesta P, Hack MA, Hartfuss E, Kettenmann H, Klinkert W, et al. (2003) Neuronal or glial progeny: regional differences in radial glia fate. Neuron 37: 751-764.

59. Kesavapany S, Li BS, Pant HC (2003) Cyclin-dependent kinase 5 in neurofilament function and regulation. Neurosignals 12: 252-264.

60. Shaw G (1998) Neurofilaments Springer-Verlag, Berlin.

61. Shaw G, Weber K (1982) Differential expression of neurofilament triplet proteins in brain development. Nature 298: 277-279. 
62. Carden MJ, Trojanowski JQ, Schlaepfer WW, Lee VM (1987) Two-stage expression of neurofilament polypeptides during rat neurogenesis with early establishment of adult phosphorylation patterns. J Neurosci 7: 3489-3504.

63. Ramírez JM, Triviño A, De Hoz R, Ramírez AI, Salazar JJ, et al. (1999) Immunohistochemical study of rabbit choroidal innervation. Vision Res 39: 1249-1262.

64. Margittai M, Fasshauer D, Pabst S, Jahn R, Langen R (2001) Homo- and heterooligomeric SNARE complexes studied by site-directed spin labeling. J Biol Chem 276: 13169-13177.

65. Yelamanchili SV, Reisinger C, Becher A, Sikorra S, Bigalke H, et al. (2005) The C-terminal transmembrane region of synaptobrevin binds synaptophysin from adult synaptic vesicles. Eur J Cell Biol 84: 467-475.

66. Iyengar B (2011) Biogenic amines and tumor-vascular interaction in melanomas. Journal of Solid Tumors, 1: 44-55.

67. Becher A, Drenckhahn A, Pahner I, Margittai M, Jahn R, et al. (1999) The synaptophysin-synaptobrevin complex: a hallmark of synaptic vesicle maturation. J Neurosci 19: 1922-1931.

68. Ahmari SE, Buchanan J, Smith SJ (2000) Assembly of presynaptic active zones from cytoplasmic transport packets. Nat Neurosci 3: 445-451.

69. Simon HH, Bhatt L, Gherbassi D, Sgadó P, Alberí L (2003) Midbrain dopaminergic neurons: determination of their developmental fate by transcription factors. Ann N Y Acad Sci 991: 36-47.

70. Wallen A, Perlman T (2003) Transcriptional Control of Dopamine Neuron Development. Ann NY Acad Sci 991: 48-60.

71. Hynes M, Rosenthal A (1999) Specification of dopaminergic and serotonergic neurons in the vertebrate CNS. Curr Opin Neurobiol 9: 2636.

72. Ye W, Shimamura K, Rubenstein JL, Hynes MA, Rosenthal A (1998) FGF and Shh signals control dopaminergic and serotonergic cell fate in the anterior neural plate. Cell 93: 755-766.

73. Hobert O (2008) How to make dopamine neurons: ebrief: Neural Stem Cells: The New York Academy of Sciences.

74. Sugden D (1989) Melatonin biosynthesis in the mammalian pineal gland. Experientia 45: 922-932.

75. Iyengar B (1996) Photoresponses of melanocytes. The circadian rhythm and proliferation. Growth Disorders of the Pigment Cells. BI Churchill Livingstone, New Delhi.

76. Graham DG (1979) On the origin and significance of neuromelanin. Arch Pathol Lab Med 103: 359-362.

77. Nagatsu T, Numata(Sudo) Y, Kato T, Sugiyama K, Akino M (1978) Effects of melanin on tyrosine hydroxylase and phenylalanine hydroxylase. Biochim Biophys Acta 523: 47-52.

78. Miranda, M, Botti, D, Ventura, T, Bonfigli, A, Arcadi, A, et al. (1985) Melanogenesis in human substantia nigra. Pigment Cell, Univ. of Tokyo Press, Tokyo, Japan.

79. Williams PL, Warwick R, Dyson M, Bannister LH (1989) Gray's Anatomy. (37thedn. Churchill Livingstone, London.

80. Carpenter MB (1945) Core Textbook of Neuro anatomy. (3rdedtn) Williams and Wilkins, Baltimore, USA.

81. Iyengar B (1992) Neural differentiation as an expression of UV sensitivity of melanocytes. Acta Anat (Basel) 143: 236-240.

82. Iyengar B (1992) Melanocytes--a UV-sensitive neural network and circadian rhythms. Acta Anat (Basel) 144: 332-335.

83. Iyengar B (1994) UV guided dendritic growth patterns and the networking of melanocytes. Experientia 50: 669-672.

84. Rolls MM, Albertson R, Shih HP, Lee CY, Doe CQ (2003) Drosophila aPKC regulates cell polarity and cell proliferation in neuroblasts and epithelia. J Cell Biol 163: 1089-1098.

85. Doe CQ (1992) Molecular markers for identified neuroblasts and ganglion mother cells in the Drosophila central nervous system. Development 116: 855-863.

86. Zhong W (2003) Diversifying neural cells through order of birth and asymmetry of division. Neuron 37: 11-14.
87. Kasemeier-Kulesa JC, Teddy JM, Postovit LM, Seftor EA, Seftor RE, et al. (2008) Reprogramming multipotent tumor cells with the embryonic neural crest microenvironment. Dev Dyn 237: 2657-2666.

88. Hochedlinger K, Blelloch R, Brennan C, Yamada Y, Kim M, et al. (2004) Reprogramming of a melanoma genome by nuclear transplantation. Genes Dev 18: 1875-1885.

89. Takahashi K, Tanabe K, Ohnuki M, Narita M, Ichisaka T, et al. (2007) Induction of pluripotent stem cells from adult human fibroblasts by defined factors. Cell 131: 861-872.

90. Yu J, Vodyanik MA, Smuga-Otto K, Antosiewicz-Bourget J, Frane JL, et al. (2007) Induced pluripotent stem cell lines derived from human somatic cells. Science 318: 1917-1920.

91. Hendrix MJ, Seftor EA, Seftor RE, Kasemeier-Kulesa J, Kulesa PM, et al. (2007) Reprogramming metastatic tumour cells with embryonic microenvironments. Nat Rev Cancer 7: 246-255.

92. Real C, Glavieux-Pardanaud C, Le Douarin NM, Dupin E (2006) Clonally cultured differentiated pigment cells can dedifferentiate and generate multipotent progenitors with self-renewing potential. Dev Biol 300: 656-669.

93. Graham A, Begbie J, McGonnell I (2004) Significance of the cranial neural crest. Dev Dyn 229: 5-13.

94. Kulesa P, Ellies DL, Trainor PA (2004) Comparative analysis of neural crest cell death, migration, and function during vertebrate embryogenesis. Dev Dyn 229: 14-29.

95. Harris ML, Erickson CA (2007) Lineage specification in neural crest cell pathfinding. Dev Dyn 236: 1-19.

96. Le Douarin NM, Dupin E (2003) Multipotentiality of the neural crest. Curr Opin Genet Dev 13: 529-536.

97. Le Douarin NM1, Creuzet S, Couly G, Dupin E (2004) Neural crest cell plasticity and its limits. Development 131: 4637-4650.

98. Bronner-Fraser M1, Fraser SE (1988) Cell lineage analysis reveals multipotency of some avian neural crest cells. Nature 335: 161-164.

99. Tickle C, Trinkaus JP (1976) Observations on nudging cells in culture. Nature 261: 413.

100. Bilozur, ME, Hay, ED. (1988) Neural crest migration in 3D extracellular matrix utilizes laminin, fibronectin, or collagen. Dev Biol 125: 19-33.

101. Hay ED (2004) The extracellular matrix in development and regeneration. An interview with Elizabeth D. Hay. Int J Dev Biol 48: 687-694.

102. Mintz B, Illmensee K (1975) Normal genetically mosaic mice produced from malignant teratocarcinoma cells. Proc Natl Acad Sci U S A 72: 3585-3589.

103. Topczewska JM, Postovit LM, Margaryan NV, Sam A, Hess AR, et al. (2006) Embryonic and tumorigenic pathways converge via Nodal signaling: role in melanoma aggressiveness. Nat Med 12: 925-932.

104. Kulesa PM, Kasemeier-Kulesa JC, Teddy JM, Margaryan NV, Seftor EA, et al. (2006) Reprogramming metastatic melanoma cells to assume a neural crest-cell like phenotype in an embryonic microenvironment. PNAS 103: 3752-3757.

105. Bhatavdekar JM1, Patel DD, Vora HH, Shah NG, Karelia NH, et al. (1994) Prolactin: its role in advanced tongue cancer. J Surg Oncol 57: 115-120.

106. Bhatavdekar JM1, Patel DD, Chikhlikar PR, Shah NG, Vora HH, et al. (2001) Ectopic production of prolactin by colorectal adenocarcinoma. Dis Colon Rectum 44: 119-127.

107. Clevenger CV1, Kline JB (2001) Prolactin receptor signal transduction. Lupus 10: 706-718.

108. Bole-Feysot C1, Goffin V, Edery M, Binart N, Kelly PA (1998) Prolactin (PRL) and its receptor: actions, signal transduction pathways and phenotypes observed in PRL receptor knockout mice. Endocr Rev 19: 225-268.

109. Brockman JL1, Schroeder MD, Schuler LA (2002) PRL activates the cyclin D1 promoter via the Jak2/Stat pathway. Mol Endocrinol 16: 774-784. 
Citation: $\quad$ lyengar B (2014) Tumor Vascular Interaction in Melanomas and Neurogenesis: A Review. Pigmentary Disorders 1: 112. doi:10.4172/ jpd.1000112

Page 12 of 12

110. Berridge MJ (1993) Inositol trisphosphate and calcium signalling. Nature 361:315-325.

111. Vacher P, Van Chuoi MT, Paly J, Djiane J, Dufy B (1994) Short term effect of prolactin on intracellular calcium in Chinese hamster ovary cells stably transfected with prolactin receptor complementary deoxyribonucleic acid. Endocrinol 134: 1213-1218.

112. Prevarskaya N1, Skryma R, Vacher P, Daniel N, Bignon C, et al. (1994) Early effects of PRL on ion conductances in CHO cells expressing PRL receptor. Am J Physiol 267: C554-562.

113. Iyengar B (1995) Corticotropin expression by human melanocytes in the skin. Pigment Cell Res 8: 142-146.

114. Rousseau K, Kauser S, Pritchard LE, Warhurst A, Oliver RL, et al. (2007) Proopiomelanocortin [POMC], the $\mathrm{ACTH} /$ melanocortin precursor, is secreted by human epidermal keratinocytes and melanocytes and stimulates melanogenesis. FASEB J 21: 1844-1856.
115. Slominski A, Wortsman J, Pisarchik A, Zbytek A, Linton EA, et al. (2001) Cutaneous expression of corticotrophin releasing hormone [CRH], urocortin and CRH receptors. FASEB J 15: 1678-1693.

116. Slominski A, Tobin DJ, Shibahara S, Wortsman J (2004) Melanin pigmentation in mammalian skin and its hormonal regulation. Physiol Rev 84: 1155-1228.

117. Ziegler CG, Krug AW, Zouboulis CC, Bornstein SR (2007) Corticotropin releasing hormone and its function in the skin. Horm Metab Res 39: 106-109.

118. Iyengar B, Timar J, Szende B (1996) Modulation of cell cycle traverse in the amelanotic cells of vitiligo and melanomas. The interphase between aplasia and neoplasia. Growth Disorders of the Pigment Cell. BI Churchill Livingstone, New Delhi.

119. Tsatmali M, Ancans J, Thody AJ (2002) Melanocyte function and its control by melanocortin peptides. J Histochem Cytochem 50: 125-133. 